\title{
Processos educativos inerentes ao "fazer o samba" por Bezerra da Silva (1927-2005) e a produção do conhecimento em espaços não escolares
}

\author{
Tiago Zanquêta de Souza \\ Universidade de Uberaba - UNIUBE, Brasil \\ Aldiôney Pereira de Melo \\ Universidade de Uberaba - UNIUBE, Brasil
}

\section{RESUMO}

Este artigo tem como objetivo identificar processos educativos inerentes ao "fazer o samba" por Bezerra da Silva (1927-2005). Está ancorado no referencial da Educação Popular, por meio da revisão de literatura. A expressão das vozes do samba sofreu preconceitos e um intenso processo de marginalização. Porém, a capacidade de resistência, fruto das privações materiais decorrentes da exclusão social forjou, no interior das comunidades cariocas, uma outra tessitura social. Assim, as comunidades encontraram no samba e nas demais manifestações artísticas, a instrumentalização metodológica necessária para a construção de saberes e denúncia das injustiças. Em outros termos, o samba de Bezerra da Silva cumpriu seu papel educativo, importante naquelas comunidades esquecidas pelo poder público e, muitas vezes, desconhecidas pela educação escolar.

PALAVRAS-CHAVE: Prática Social. Processos Educativos. Samba.

\section{EDUCATIONAL PROCESSES INHERENT IN "DOING THE SAMBA" BY BEZERRA DA SILVA (1927-2005) AND THE PRODUCTION OF KNOWLEDGE IN NON-SCHOOL SPACES}

\begin{abstract}
This article aims to identify educational processes inherent in "doing the samba" by Bezerra da Silva (1927-2005). It is anchored in the Popular Education referential, through literature review. The expression of the samba voices suffered prejudices and an intense process of marginalization. However, the capacity for resistance, as a result of the material deprivations due to social exclusion, forged within the communities of Rio de Janeiro another social fabric. Thus, the communities found in the samba and other artistic manifestations, the methodological instrumentalization necessary for the construction of knowledge and denunciation of injustices. In other words, the samba of Bezerra da Silva fulfilled its educational role, important in those communities forgotten by the public power and, often, unknown by the school education.
\end{abstract}

KEYWORDS: Social Practice. Educational Processes. Samba. 


\section{PROCESOS EDUCATIVOS INHERENTES DEL "HACER EL SAMBA" POR BEZERRA DA SILVA (1927-2005) Y LA PRODUCCIÓN DEL CONOCIMIENTO EN ESPACIOS NO ESCOLARES}

\section{RESUMEN}

Este artículo tiene como objetivo identificar procesos educativos inherentes al "hacer el samba" por Bezerra da Silva (1927-2005). Está anclado en el referencial de la Educación Popular, por medio de la revisión de literatura. La expresión de las voces del samba sufrió preconceptos y un intenso proceso de marginación. Sin embargo, la capacidad de resistencia, fruto de las privaciones materiales derivadas de la exclusión social, forjaron, dentro de las comunidades cariocas, otra tesitura social. Así, las comunidades encontraron en el samba y en las demás manifestaciones artísticas, la instrumentalización metodológica necesaria para la construcción de saberes y denuncia de las injusticias. En otros términos, el samba de Bezerra da Silva cumplió su papel educativo, importante en aquellas comunidades olvidadas por el poder público y, muchas veces, desconocidas por la educación escolar.

PALABRAS CLAVE: Práctica Social. Procesos Educativos. Samba.

\section{INTRODUÇÃO}

Este artigo é fruto de uma elaboração realizada a partir da provocação de uma disciplina do curso de Mestrado em Educação, que tem por objetivo, partindo de uma compreensão de educação como cultura, identificar processos educativos inerentes ao "fazer o samba" por Bezerra da Silva (1927-2005).

Está ancorado no referencial teórico da Educação Popular, especialmente nos trabalhos de Paulo Freire (2005), Oliveira et al. (2014), Araújo-Olivera (2014) e Carlos Rodrigues Brandão $(2002,2009)$.

Compreendemos que a Educação Popular é uma visão de mundo que prima pela construção de um conhecimento que vai no sentido do fazer história. Segundo Paulo Freire (2005), a história também é feita quando, ao surgirem os novos temas, o ser humano propõe uma nova formulação, uma mudança na maneira de atuar, nas atitudes e nos comportamentos. A Educação Popular concebida nesse trabalho é aquela que exprime um conteúdo que se origina na realidade, por meio de uma base política enquanto promotora da superação do silêncio imposto em cada um/uma; que prioriza a preparação intelectual dos/as cidadãos/ãs; que leva à construção moral de um grupo estigmatizado; que potencializa a capacidade de direção política das pessoas e, por último, que apresenta uma visão pedagógica que todos/as aprendem conjuntamente.

Quanto aos procedimentos metodológicos da pesquisa, estão calcados nos pressupostos da abordagem qualitativa, assim organizados: num primeiro momento, realizou-se a revisão bibliográfica, conforme orientam Lüdke; André (2015). Num segundo momento, fez-se um 
levantamento histórico em torno da vida e obra de Bezerra da Silva (1927-2005) para, em seguida, fazer a seleção dos sambas por ele interpretados, com a finalidade de, a partir deles e neles, desvelar os processos educativos e revelar a produção do conhecimento em espaços não escolares.

Partimos do entendimento de que ocorre intensa produção de conhecimento em espaços e contextos não escolares, ou seja, ligados aos diferentes meios em que as pessoas estão inseridas. A busca é pela valorização dos saberes de experiência feito (FREIRE, 2005), no cuidado de compreender e entender os modos de viver das pessoas, suas escolhas e os tipos de ações/atividades realizados, de modo a transformar sua realidade. O "fazer o samba", enquanto prática social, configura-se por meio dos acontecimentos do dia a dia, cujo conteúdo tem origem na necessidade do enfrentamento da opressão, do preconceito, da discriminação, na denúncia da injustiça social.

O artigo está estruturado da seguinte maneira: primeiro, fez-se uma discussão em torno da prática social do "fazer o samba", para, em seguida, promover uma reflexão em torno dessa prática social, com a finalidade de desvelar os processos educativos e elucidar a produção do conhecimento em espaços não escolares, contexto em que o samba tem sua origem, uma vez que aqui ele é considerado como uma forma de produção e sistematização do conhecimento popular.

\section{A PRÁTICA SOCIAL DO "FAZER O SAMBA"}

Por ser a expressão das vozes periféricas, o samba enfrentou o preconceito de grande parte da sociedade, chegando, inclusive, a ser criminalizado. Para se ter uma dimensão do preconceito sofrido pelo samba no início do século XX, basta analisar os ataques recorrentes que o funk vem sofrendo no século XXI. Recentemente, tramitou no Senado Federal mais um ataque direto ao direito de livre expressão e manifestação de milhões de brasileiros. A Ideia Legislativa $^{1}$ (SUGESTÃO n $^{\circ} 17$ de 2017) que tentava criminalizar o gênero musical funk e as manifestações culturais dele recorrentes teve o mérito analisado pelo Senado e a ação foi julgada inconstitucional, portanto, arquivada.

Ao refutar a SUGESTÃO nº 17, o relator, Senador Romário, diz o seguinte:

Com efeito, nos parece ser um grande equívoco relacionar a ocorrência de eventuais atos criminosos durante os bailes funk com a manifestação artística e cultural que advém da música. Os bailes entretêm a juventude. Trazem

\footnotetext{
${ }^{1}$ É um instrumento de exercício da cidadania em que o cidadão comum pode propor um projeto de lei e compartilhar o link com o conjunto da sociedade. Esse instrumento está disponível no Portal E-Cidadania que foi criado em 2012 pelo Senado Federal.
} 
divertimento para uma grande parcela da população, justamente para aquela que já se sente marginalizada pela pobreza e exclusão social. Vemos o funk como uma forma de manifestação de pensamento desses jovens, uma maneira de serem vistos e de se sentirem participantes da sociedade civil.

O relatório final apresentado pelo referido Senador apresenta argumentos consistentes e verdadeiros, uma vez que apenas as letras frias das garantias constitucionais não proporcionam, de fato, às comunidades periféricas e marginalizadas, condições mínimas de sociabilidade e exercício da cidadania.

Essa tentativa frustrada de amordaçar a voz da periferia representa apenas uma dentre tantas outras formas de marginalização das práticas e expressões culturais das camadas menos favorecidas da sociedade brasileira.

Não se pode pensar a cultura e as manifestações populares sem, no entanto, tomar como referência o processo histórico de formação da nação brasileira, a qual foi forjada a partir do calor dos corpos dos negros escravizados. A população negra do Brasil foi desenraizada de sua cultura, alijada de qualquer direito, tratada como animal, trancafiada em senzalas e, após a abolição de 1888, abandonada à própria sorte, carregando consigo os estigmas de uma vida de privações, maus-tratos e preconceitos. Ao analisar o processo histórico de criminalização do negro no Brasil, Ênio Filho afirma:

[...] somado a estes estigmas formaram-se ainda os estigmas culturais, em que toda religião advinda de negros seria a própria encarnação do mal. Aliás, tudo que se originasse dos negros, já estigmatizados, símbolos da não humanidade, fora também marcado. O "negro conceitual" é um conjunto de atributos culturais, físicos, psicológicos ligados à cultura da senzala que depois se tornou gueto, periferia (OLIVEIRA FILHO, 2016 p. 64).

Sem possibilidade de convívio social, indesejada inclusive para o trabalho, sem direitos e sem moradia, essa gente passou a desenvolver seus próprios mecanismos de sobrevivência e recriou novas práticas sociais, as quais, segundo Oliveira, et al. (2014, p. 33),

[...] decorrem de e geram interações entre os indivíduos e entre eles e os ambientes natural, social e cultural em que vivem. Desenvolvem-se no interior de grupos, de instituições, com propósito de produzir bens, transmitir valores, significados, ensinar a viver e controlar o viver; enfim, manter a sobrevivência material e simbólica das sociedades humanas. As práticas sociais tanto podem enraizar como desenraizar ou levar a criar novas raízes.

As interações decorrentes dessas práticas desenvolveram valores, saberes e bens que possibilitaram que emergisse, do interior desse convívio, um novo processo de enraizamento, capaz de expressar a resiliência, a força e a resistência daqueles que foram historicamente marginalizados. Dentre uma infinidade de práticas sociais existentes nas periferias, 
destacaremos como elemento de análise o samba, porque, assim como o funk, ele também foi objeto de perseguição e marginalização.

Discutindo sobre a construção/invenção do samba, Miguel Jost (2015, p.122) apresenta alguns elementos que corroboram essa percepção.

O samba nasceu em bairros da cidade e não nas favelas, num trânsito que colocava distintos atores e instituições em diálogo [...]. Porém, quanto mais marginalizado o trabalhador negro, o morro, por ser um lugar com um sistema de poder e de gestão próprios, pode abrigá-lo, tanto em sua expressão cultural - ainda vista como "violenta"[...].

Não entraremos no mérito ou na polêmica de demarcação da origem do samba, porque não é essa a finalidade deste artigo. Aqui, nos interessa apenas a percepção histórica que analisa as condições pelas quais o samba fincou suas raízes nos morros cariocas, tornando-se o portavoz daqueles que foram silenciados pela exclusão social, mas, que através das manifestações culturais, conseguiram dizer quem eram, de onde vieram, o que faziam, como viviam, o que queriam e, sobretudo, o que não mais suportariam.

Elegeu-se, para elaboração desse artigo, em função do seu poder de comunicação e sobretudo pelo seu caráter pedagógico, o samba de Bezerra da Silva (1927-2005), que ficou conhecido como "o embaixador da favela" e que foi estigmatizado como "cantor de bandido", simplesmente, porque denunciava a injustiça social e expressava a dura realidade da periferia, especialmente do Rio de Janeiro.

\section{INTERPRETAR O SAMBA: PROCESSOS EDUCATIVOS E A PRODUÇÃO DO CONHECIMENTO EM ESPAÇOS NÃO ESCOLARES}

Faz-se necessário apresentar nesta seção o que entendemos por espaços não escolares, o conceito de cultura popular que emerge da tessitura social do "fazer o samba" e, finalmente, a estratégia utilizada pelo artista em foco, para escolha das letras dos sambas por ele interpretado, alvo de análise desse artigo.

Sérgio Haddad (2016, p.378), ao apresentar um dossiê sobre educação não escolar, lançou mão de uma metáfora muito interessante para diferenciá-la da educação escolar.

Nossa intenção ao coordenar esta série de estudos foi a de dar um passo a mais no conhecimento daquilo que, na metáfora do iceberg, corresponde à sua parte imersa e quase invisível na formação dos seres humanos: a educação não escolar. A educação escolar, que corresponde à parte visível, é aquela na qual se concentra o maior número de estudos e onde o conhecimento científico acumulado tem sido maior. 
Conforme descrito pelo autor, a educação não escolar é a parte submersa de um imenso iceberg. É o resultado da interação entre os sujeitos e suas práticas sociais cotidianas. A educação não escolar pode ter ou não algum tipo de institucionalidade.

A obra de Bezerra da Silva anuncia as possibilidades de se fazer e de acontecer a educação em contextos não escolares, nos meandros das comunidades populares, que configuram um espaço singular no processo de produção do conhecimento.

Como se sabe, mesmo sem guardar vínculo institucional e/ou qualquer outra forma de instrumentalização pedagógica, as interações decorrentes das práticas sociais geram e intensificam processos formativos capazes de integrar ações e saberes que, em constante processo de sistematização, propiciam articulação entre ensino e aprendizagem dos e nos agentes envolvidos.

A cultura pode ser compreendida, definida e conceituada a partir várias perspectivas. Porém, o conceito de Cultura Popular aqui empregado está alicerçado nas reflexões de Carlos Brandão, tendo em vista que ele é crítico do processo de classificação entre as culturas e defende a tese de que

[...] quando falamos de povo ou de cultura popular estamos lidando com palavras que alguém - um professor, um pesquisador, um intelectual, um erudito, enfim - criou para significar, do seu ponto de vista, quem é e o que faz e cria um outro que não ele mesmo (BRANDÃO, 209, p.727).

Em outros termos, a diferenciação classificatória - cultura erudita, cultura popular ou subalterna - está relacionada ainda à ideia do evolucionismo cultural, em que, a medida de referência, era o conceito de civilização elaborado pelos europeus em meados do século XIX. Essa visão etnocêntrica foi refutada pela antropologia, mas, mesmo assim, permaneceu viva como instrumento ideológico de dominação.

A cultura é viva e permanece em intensa movimentação, cuja interação produz e reproduz a existência material e imaterial da vida humana. Não existe dicotomia, oposição ou verticalização de culturas, uma vez que o processo de sua hibridação é dinâmico e horizontal. Para corroborar esses argumentos e deixar bem clara tal concepção sobre Cultura Popular, Brandão recorre a Canclini (1983) que afirma:

[...] a especificidade das culturas populares não deriva apenas do fato de que a sua apropriação daquilo que a sociedade possui seja menor e diferente; deriva também do fato de que o povo produz no trabalho e na vida formas específicas de representação, reprodução e reelaboração simbólica de suas relações sociais. [...] $\mathrm{O}$ povo realiza estes processos compartilhando as condições gerais de produção, circulação do sistema em que vive [...] Portanto, as culturas populares são construídas em dois espaços: a) as práticas profissionais familiares, comunicacionais e de todo tipo através dos quais o sistema capitalista organiza a vida de todos os seus membros; b) as práticas e 
formas de pensamento que os setores populares criam para si próprios, mediante os quais concebem e expressam a sua realidade, o seu lugar subordinado na produção, na circulação e no consumo (CANCLINI, 1983, p.43, apud BRANDÃO, 2009. p.728).

É a partir desta percepção, a de Canclini (1983, p.43, apud BRANDÃO, 2009. p.728) "que o povo produz no seu trabalho e na vida formas específicas de representação, reprodução e reelaboração simbólica", que compreendemos o potencial educativo contido nos sambas interpretados por Bezerra da Silva.

\subsection{Os processos educativos decorrentes da prática "fazer o samba" por Bezerra da Silva}

José Bezerra da Silva nasceu na cidade do Recife-PE em 23 de fevereiro de 1927 e faleceu no dia 17 janeiro de 2005 no Rio de Janeiro. A sua história como migrante não é muito diferente daquela descrita por Belchior na letra da música "Fotografia $3 \times 4$ ", na qual ele expressa o drama e as angústias de um jovem retirante durante a segunda metade do século XX, nas grandes cidades do sudeste brasileiro.

Em cada esquina que eu passava um guarda me parava

Pedia os meus documentos e depois sorria

Examinando o $3 \times 4$ da fotografia

E estranhando o nome do lugar de onde eu vinha [...]

Esses casos de família e de dinheiro eu nunca entendi bem

Veloso, o sol não é tão bonito pra quem vem do Norte e vai viver na rua

A noite fria me ensinou a amar mais o meu dia

E pela dor eu descobri o poder da alegria

E a certeza de que tenho coisas novas

Coisas novas pra dizer $[\ldots]$

Bezerra da Silva trabalhou na construção civil e teve como moradia os próprios canteiros de obras. Depois, conseguiu guarida no Morro do Cantagalo na periferia do Rio de Janeiro e, segundo ele próprio, viveu na rua por um bom tempo. Conheceu a miséria e sentiu na pele o peso da exclusão social. Como diz a letra da música de Belchior, pela dor ele descobriu o poder da alegria e com certeza nos disse coisas muito velhas, mas que permanecem novas.

Quando jovem, Bezerra teve a oportunidade de estudar música e desenvolver a habilidade de tocar alguns instrumentos musicais, cujo capital cultural incorporado ${ }^{2}$ favoreceu seu ingresso, com destaque, no universo do samba. Estudioso, determinado e extremamente versátil, aproveitou cada uma das oportunidades e se transformou em um dos principais expoentes do samba, deixando uma obra extremamente rica em musicalidade e de um valor histórico/cultural imensurável.

\footnotetext{
${ }^{2}$ Primeiro estágio do Capital Cultural, conceito elementar para compreender a estrutura hierárquica de poder e privilégios denunciados pela Sociologia de Pierre Bourdieu (1999).
} 
Para potencializar sua crítica social e dizer a verdade do cotidiano, como ele mesmo gostava de afirmar, percorria os guetos, morros e favelas em busca dos compositores que expressassem, com criatividade e acidez, o cotidiano de suas respectivas comunidades. Em uma entrevista concedida ao documentário "Onde a Coruja Dorme", Bezerra demonstra um certo aborrecimento com o preconceito e as tentativas de estigmatização que sofria em função da acidez e da origem de seus letristas. Ao se referir aos compositores ele disse: "então, como eles dizem a realidade que dói, eles aí dizem que eu sou cantor de bandido. Porque os autores que escrevem pra mim são favelados 3 ". Em uma outra fala, ele apresenta um exemplo muito marcante para reforçar a capacidade de percepção e expressão da realidade, bem como o talento nato de um grupo de pessoas que foi privado do ensino escolar ou qualquer instrução musical e, mesmo assim, conseguiu produzir músicas com riqueza poética e melódica.

Mas o compositor aqui do morro, ele é analfabeto duas vezes: musical e de instrução. Então ele faz uma melodia, que depois ele também não sabe o que que é, porque eu já tive essa experiência, que é muito bonita, cheia de acidentes, sustenidos, bemóis. Eu já tirei melodias e depois toquei no piano pra eles e perguntei: "de quem é isso aqui?" - "Num sei, não". Depois ele vai ouvindo: "acho que eu conheço isso". Eu falo: isso aqui é seu4.

Ao explorar os depoimentos dos compositores e do próprio cantor, temos a percepção de que a potencialidade socioeducativa dos sambas interpretados por Bezerra da Silva decorre da estreita interação entre o cantor/produtor com seus compositores e destes com a comunidade em que estavam inseridos.

Bezerra da Silva não é um estranho que subia ao morro para buscar letras de samba, comprar uma canção ou simplesmente usurpar a composição alheia. Guardadas as devidas proporções, espaços e temporalidades, ele desenvolvia pesquisas que se assemelham muito ao universo acadêmico de grupos de estudos preocupados em investigar processos educativos em práticas sociais. Vejamos, como exemplo e parâmetro para essa afirmativa, as reflexões epistemológicas e metodológicas de Sônia Stela Araújo-Olivera ao discorrer sobre a pesquisa em práticas sociais:

Inserir-se, estabelecer relações de confiança, estar aberto ao Outro, faz parte da postura ético-político e também influencia as maneiras de construir as abordagens metodológicas. Embora as pesquisadoras sejam e se assumam responsáveis pelas tomadas de decisões perante a comunidade acadêmica, os percursos das pesquisas vão se construindo, o vaivém de diálogos e reflexões gerados na proximidade, no face a face com o Outro, ombro a ombro na comunidade de trabalho, na convivência, a partilha do fazer junto com o Outro, na urdidura em que se articulam as experiências, com outros estudiosos

\footnotetext{
${ }^{3}$ Entrevista de Bezerra da Silva - Documentário Onde a coruja dorme, Márcia Derraik e Simplício Neto, Antenna \& TV Zero, Rio de Janeiro, Brasil, 2006.

${ }^{4}$ Idem à nota 3 , anterior.
} 
e na troca de experiências dos pesquisadores do grupo (ARAÚJO-OLIVERA, 2014, p. 61).

Observa-se que a autora descreve um conjunto de saberes que são elementares para o universo da pesquisa - estabelecer relações de confiança, assumir responsabilidade, proximidade, diálogo, partilhar e fazer junto - em que o outro é parte integrante, portanto, partícipe do processo.

Empiricamente, Bezerra da Silva dominava todos esses elementos, porque ele não era um estranho qualquer que pretensiosamente observou panoramicamente o desenvolver das práticas sociais de terceiros. Bezerra da Silva viveu e conviveu com e na periferia, cantava com e para o povo marginalizado.

Portanto, pela capacidade de relacionamento, pela fidelidade, por assumir a responsabilidade que o trabalho de intérprete/produtor lhe conferia, por fazer junto, por compartilhar experiências, Bezerra da Silva conseguiu interferir positivamente na vida de milhares de pessoas. Como recompensa, recebeu o respeito e a admiração de quase todos aqueles/as que se sentiam e ainda se sentem excluídos/as, oprimidos/as, esquecidos/as e marginalizados/as.

Os sambas interpretados por Bezerra da Silva podem ser compreendidos como uma tentativa de sistematização da sabedoria que emergia das práticas sociais cotidianas da periferia carioca. Portanto, nesses espaços onde a educação escolar não conseguira se fazer presente, as manifestações culturais assumiram papel importante no processo de construção de valores e moralidade própria dos espaços marginalizados. Sendo assim, os letristas anunciavam, cantando, o conjunto de saberes e princípios necessários para a convivência e a sobrevivência nos guetos, morros e favelas.

Oliveira et al. (2014, p.35) afirmam que "nas práticas sociais promove-se formação para a vida na sociedade por meio de processos educativos que essas desencadeiam: assim tem sido em todas as sociedades ao longo da história humana". Sendo assim, doravante serão apresentados fragmentos de letras de músicas e/ou trechos de entrevistas de Bezerra da Silva para fins de análise e identificação dos processos educativos presentes nos seus sambas.

Dentre os elementos identificados como processos educativos que se fazem presentes nos sambas de Bezerra, podem-se destacar: conhecimento e compreensão de sua própria realidade; criação e transmissão de códigos de condutas; construção de formas simbólicas de comunicação; entre muitos outros saberes.

Para transformar sua realidade, como propõe Paulo Freire (2005) e superar as adversidades, é necessário que cada um dos sujeitos seja capaz de apreender a dinâmica das 
relações interpessoais, decodificar a linguagem própria do seu grupo, internalizar os códigos de conduta, bem como compreender os processos de produção e reprodução da vida cotidiana no interior da sua respectiva comunidade. Na música "Campo Minado"5 percebe-se a transmissão de códigos de condutas que devem ser compreendidos, e a construção dos conhecimentos que são internalizados e respeitados.

Tem muita gente rodeando a gente / seja mais decente / senão de repente você dança / e se não falar a linguagem certa / tem homem de alerta / mesmo não ventando a roseira balança.

Vai devagar na cerveja / e no particular vai só se for chamado / não entre na porta da frente / que evidentemente é lugar reservado / preste atenção no que fala / porque o ambiente exige cuidado / haja com muita cautela / pisando de leve que o campo é minado...

São orientações direcionadas àqueles/as que ainda não conhecem a dinâmica e nem as demarcações das relações sociais próprias daquele espaço. Em outra canção - "Malandro demais vira bicho"6 - a advertência se dirige aos que demonstram algum entusiasmo no sentido de projeção de uma imagem relacionada ao universo do crime.

Você diz a todo mundo / coisas que você não faz / e na roda de malandro / todos me chamam malandro demais / deixa disso rapaz...

Eu já disse a você / que malandro demais / ele vira bicho / e também já lhe pedi /pra você parar com isso...

A música "Se não fosse o samba"7 denuncia o preconceito e a truculência policial, mas também apresenta possibilidade de superação da situação fora do crime.

E se não fosse o samba / quem sabe hoje em dia eu seria do bicho?

Não deixou a elite me fazer marginal / E também em seguida me jogar no lixo /a minha babilaque era um lápis e papel no bolso da jaqueta / uma touca de meia na minha cabeça / Uma fita cassete gravada na mão.

E toda vez que descia o meu morro do galo / eu tomava uma dura / os homens voavam na minha cintura / pensando encontrar aquele três oitão / mas como não achavam / ficavam mordidos não dispensavam / abriam a caçapa e lá me jogavam / mais uma vez na tranca dura pra averiguação.

Batiam meu boletim / o nada consta dizia: ele é um bom cidadão /o cana-dura ficava muito injuriado / porque era obrigado a me tirar da prisão.

Mas hoje em dia eles passam / me veem e me abraçam, me chamam de amigo /os que são compositores gravam comigo / e até me oferecem total proteção.

Humildemente agradeço / e digo pra eles: estou muito seguro / porque sou bom malandro/e não deixo furo/e sou considerado em qualquer jurisdição.

\footnotetext{
${ }^{5}$ Vantuil do Salgueiro (Comp.). Malandro é malandro e mané é mané. CD. "Campo minado". Faixa 9. São Paulo: Atração Fonográfica, 2000.

${ }^{6}$ Nilo Dias (Comp.) Partido alto nota 10. LP. "Malandro demais vira bicho". Lado A, Faixa 2. Rio de Janeiro; CID, 1977.

${ }^{7}$ Carlinhos Russo e Zezinho do Valle (Comp.). Se não fosse o samba. LP. "Se não fosse o samba". Lado B, faixa 2. São Paulo: RCA, 1989.
} 
Observa-se que além das denúncias sociais existe também a preocupação na formação dos sujeitos. Os sambistas apreenderam a realidade do ser "favelado", sistematizaram o conhecimento decorrente das práticas sociais, reelaboraram cada um deles numa linguagem metafórica extremamente eficiente e, finalmente, anunciavam seus ensinamentos, orientações e exortações nas manifestações culturais de rodas de sambas.

Aqui cabe destacar o desenvolvimento e utilização da gíria como linguagem contextual, original e significativa, própria de um novo processo de enraizamento cultural de uma dada comunidade. Segundo Mikhail Bakhtin,

[...] o discurso se molda sempre à forma do enunciado que pertence a um sujeito falante e não pode existir fora dessa forma. Quaisquer que sejam o volume, o conteúdo, a composição, os enunciados sempre possuem, como unidades de comunicação verbal, características estruturais que lhes são comuns e, acima de tudo, fronteiras claramente delimitadas (BAKHTIN, 1997, p.294).

Sendo assim, as gírias impressas nas letras dos sambas carregam uma carga simbólica cheia de significados históricos e culturalmente estruturados. Se desconsiderados os limites fronteiriços e seu contexto originário, os sambas cantados por Bezerra da Silva podem ser interpretados apenas como uma simples crítica social, expressa por meio de notas melódicas de um ritmo envolvente. Porém, a linguagem não pode ser dissociada do seu contexto original, portanto, ela é dotada de sentidos e significados que são facilmente apropriados por aqueles/as que a reconhecem como parte integrante de sua própria forma de comunicação. Ainda repercutindo a já referida entrevista para o documentário “Onde a coruja dorme” Bezerra disse:

A gíria é uma cultura negra. A base dela foram os escravos que inventaram. Quando eles iam traçando o plano de fuga, eles falavam aquilo em gíria, que era para não entenderem. É justamente o que hoje os intelectuais fazem com a gente. Eles vão pra escola aprendem e tal "data vênia". Aí fala com você o dia todinho, chama você do que quer e você não entende nada. Fica só: "sim senhor, doutor; tá, doutor". Então o que que a gente faz? A gente também pode conversar com o doutor do mesmo jeito e ele ficar o dia todo sentado e não entender nada também. Aí é zero a zero.

Assim, a gíria apareceu como elemento estruturante do discurso de Bezerra da Silva e cumpriu - em função do seu potencial ilustrativo e da capacidade de anunciação - um importante papel socioeducativo nas comunidades marginalizadas da periferia carioca. Isso foi possível porque a sabedoria popular foi capaz de sistematizar o conjunto de saberes decorrentes de suas próprias práticas sociais, transformar esse conhecimento em versos e, posteriormente, expressá-los em forma de samba. O samba de Bezerra garantiu renda para os letristas, bem como entretenimento e desencadeou processos educativos para pessoas que viviam nos espaços 
abandonados pelo Estado, marginalizado pela sociedade e, possivelmente, carentes de um estudo mais aprofundado em contextos escolares.

\section{CONSIDERAÇÕES FINAIS}

Por emergir do seio das comunidades periféricas do Rio de Janeiro e expressar melodicamente a indignação, a resistência e, sobretudo, os saberes de uma gente que vivia em espaços negligenciados pelo poder público e marginalizados pelo conjunto da sociedade, o samba representou muito mais que um simples ritmo musical. Representa um instrumento de luta, momento de lazer e recurso educativo.

A obra de Bezerra da Silva (1927-2005) revela que a prática social "fazer o samba" supera a ideia de que apenas a reunião de alguns bons letristas é suficiente para composição de um samba. O "fazer o samba" exige conhecimento da comunidade, respeito aos seus pares, domínio da linguagem e muita cumplicidade entre os sujeitos, portanto, esse ambiente é marcado pela produção de saber, que tem por consequência, o desencadeamento de processos educativos.

Como exemplos dos processos educativos decorrentes da prática social "fazer o samba", considerando as letras das músicas analisadas, destacam-se: a preocupação dos sambistas em advertir os jovens da comunidade quanto ao cuidado com o mundo do crime; exortação ao trabalho; orientações sobre códigos de condutas no interior da comunidade; denúncia da truculência policial e a importância de ser um cidadão honesto.

Ao identificar os processos educativos decorrentes de tal prática social, este trabalho corrobora significativamente para a compreensão da educação como cultura, bem como ajuda a entender a metáfora do iceberg empregada por Haddad (2016), uma vez que os processos educativos identificados são decorrentes de uma prática social vivenciada em espaços não escolares, ou seja, aqueles que "correspondem à parte imersa e quase invisível da formação dos seres humanos: a educação não escolar" (HADDAD, 2016).

\section{REFERÊNCIAS}

ARAUJO-OLIVERA, Sônia Stela. Exterioridade: o outro como critério. In: OLIVEIRA, Maria Waldenez; SOUSA, Fabiana Rodrigues (Orgs). Processos educativos em práticas sociais: pesquisas em educação. São Carlos: EdUFSCar, 2014.

BAKTHIN, Mikhail. Estética da criação verbal. São Paulo: Martins Fontes, 1997.

BOURDIEU, Pierre. Escritos de educação. Petrópolis, RJ: Vozes, 1999. 
BRANDÃO, Carlos Rodrigues. Vocação de criar: anotações sobre a cultura e as culturas populares. Cadernos de Pesquisa, v.39, n.138, p.715-746, set./dez. 2009. Disponível em: http://www.scielo.br/pdf/cp/v39n138/v39n138a03.pdf. Acesso em: 22 jan. 2019.

BRANDÃO, Carlos Rodrigues. A educação como cultura. Campinas, São Paulo: Mercado das Letras, 2002.

DERRAIK, Márcia; SIMPLÍCIO NETO (Direção). Onde a Coruja Dorme. Documentário. Rio e Janeiro: Antenna \& TV Zero, 2006.

HADDAD, Sérgio. Educação não escolar de adultos: estudos sobre educação popular e educação para os direitos humanos. Revista e-Curriculum, São Paulo, v.14, n.02, p. 377-392 abr./jun.2016. Disponível em:

https://revistas.pucsp.br/index.php/curriculum/article/viewFile/29107/20346. Acesso em: 22 jan. 2019.

FREIRE, Paulo. Pedagogia do oprimido. São Paulo: Editora UNESP, 2005.

JOST, Miguel. A construção/invenção do samba: mediações e interações estratégicas. Revista do Instituto de Estudos Brasileiros. Brasil, n. 62, p. 112-125, 2015.

LÜDKE, Menga; ANDRÉ, Marli Eliza Damázio. Pesquisa em educação: abordagens qualitativas. 2.ed. Rio de Janeiro: E.P.U., 2015.

OLIVEIRA, Maria Waldenez; GONÇALVES E SILVA, Petronilha Beatriz; GONÇALVES JÚNIOR, Luiz; GARCIA-MONTRONE, Aida Victória; JOLY, Ilza Zenker. Processos educativos em práticas sociais: reflexões teóricas e metodológicas sobre pesquisa educacional em espaços sociais. In: OLIVEIRA, Maria Waldenez; SOUSA, Fabiana Rodrigues (Orgs). Processos educativos em práticas sociais: pesquisas em educação. São Carlos: EdUFSCar, 2014.

OLIVEIRA FILHO, Ênio Walcácer de. A criminalização do negro e das periferias na história brasileira. Revista Vertentes do Direito. Brasil, v. 03, n. 01, p. 60-75, 2016. Disponível em: https://sistemas.uft. edu.br/periodicos/index.php/direito/article/ download/2018/8782/. Acesso em: 22 jan. 2019.

VIANNA, Letícia C. R. Bezerra da Silva, produto do morro: trajetória e obra de um sambista que não é santo. Rio de Janeiro: Jorge Zahar, 1999.

\section{SOBRE OS AUTORES}

Doutor em Educação pela Universidade Federal de São Carlos - UFSCar, mestre em Educação pela Universidade de Uberaba - Uniube. Possui especialização em Docência do Ensino Superior e especialização em Gestão Ambiental, pelas Faculdades Integradas de Jacarepaguá - FIJ. Possui graduação em Ciências Biológicas pela Universidade de Uberaba - Uniube. Atualmente é professor da Uniube, atuando nos Cursos de Licenciaturas e de Engenharias, nas modalidades presencial e EAD. É professor no Programa de Pós-graduação em Educação - PPGE - da mesma instituição. Tem experiência na área de Educação, no Ensino Fundamental, do primeiro ao nono ano, no Ensino Médio, Técnico e 
Superior e, também, como supervisor de estágio. Tem pesquisas na área de Educação (Educação Popular, Educação Ambiental e Extensão Popular) e ciências do ambiente.

E-mail: tiago.zanqueta@hotmail.com

Aldiôney Pereira de Melo é mestrando em Educação pelo Programa de Pós-graduação em Educação da Universidade de Uberaba. Graduado em História pela Universidade de Uberaba, possui Especialização em Pedagogia da Expressão LudoCriativa por esta mesma instituição. Tem experiência na área de História e preceptoria em EAD. Atuou como Coordenador Pedagógico na Pró-Reitoria de Educação à Distância da Universidade de Uberaba (2016-2018). Atualmente é docente do Curso de História da Universidade de Uberaba e diretor de Entidade de Educação de Trânsito (INOVE).

E-mail: aldioney@gmail.com 